THEORIA ET HISTORIA SCIENTIARUM, VOL. VIII, N ${ }^{\circ} 2$

Ed. Nicolaus Copernicus University 2008

John M. Cogan

\title{
Are the Research Strategies of Philosophy Suited to the Study of Emotion?
}

\begin{abstract}
In this essay I will claim that some methodologies of western philosophy have failed us in the matter of understanding emotion insofar as they have omitted key features of the emotional experience in their accounts of emotion. I will claim that this is due to a kind of blindness that is at work in philosophy; a blindness that is a systemic blindness towards feeling. I will also suggest that an initial step that might be taken towards correction of this situation would be to adopt the ideal of rigor promoted by the phenomenologist Edmund Husserl.
\end{abstract}

\section{Introduction}

One barrier to understanding emotions is the attitude we take with respect to how they should be studied. One reason we have misunderstood emotion may be that the method we employ to understand it is ill suited to emotional phenomena; this happens because the attitude that we take toward phenomena plays a role in the suggestion of the method we eventually adopt to understand those phenomena. Take, for instance, how this might be illustrated with respect to parenting. If we adopt the attitude of the jailer with respect to children, then the method of parenting that suggests itself to us will reflect that attitude; however, if we adopt the attitude of the shepherd, then a completely different method of parenting will suggest itself to us. The difficulty here is in determining which attitude to adopt in order for the most appropriate method of parenting to naturally suggest itself where "appropriate" means suited to all that the phenomenon has to offer.

In the case of emotion, we have typically adopted an attitude of instrumentality with respect to it and, consequently, the methods we have used 
to understand emotion reflect that attitude. ${ }^{1}$ However, this attitude keeps emotion at an experiential remove from us and fails to unlock ail that the expression of emotion has to offer, especially in the way of insight, guidance, and the growth of consciousness. The attitude of instrumentality is also reflected in the clinical assumptions made concerning emotions, namely, that emotions serve only the purpose of drive reduction. Our emotional experience, however, is much richer and calls for a different attitude, one that emphasizes expression and wholeness; for this reason, I hold that, if we are to truly understand the role that the expression of emotion plays in the growth of consciousness, then, at least with respect to how we study it, we need to adopt another attitude toward emotion to the end that we avail ourselves of everything emotion has to offer us.

\section{Indications of How Emotion is Currently Studied in Philosophy}

In his recently published book, Emotions: An Essay in Aid of Moral Psychology (Roberts, 2003), Robert C. Roberts asks, "How shall we conduct an inquiry into the emotions that will serve well the study of the virtues?" (Roberts, 2003, p.4) In the passages that follow, Roberts surveys the various attempts that have been used in western philosophy to understand the emotions, offering a kind of thumbnail sketch of what each attempt was about, in his effort to bolster the need for the tack he is taking in his own study of the virtues. These comments by Roberts are particularly illuminating in that they unwittingly reveal what I take to be philosophy's central failing in its attempt to study the emotions. Indeed, they lay bare the very undergirding assumption that has grounded nearly every attempt in western philosophy to understand emotions, namely, that it is our project that determines the method that is most appropriate for studying the emotions. Or, put another way, the nature of emotion seems to have no say whatsoever in determining the method that is best suited to studying it.

Here, one might feel trapped in a kind of vicious circularity since I seem to be claiming that we must adopt a method of studying emotion that is "suited" to emotion, but in order to do so we must already know what emotion is like. However, this objection just serves to punctuate more forcefully the very point I am making because it reveals the hidden premise maintaining that the only

\footnotetext{
${ }^{1}$ By "instrumentality," I mean to draw attention to the fact that, with respect to emotion, we approach it as we would a tool or instrument whose meaning is not contained within itself but beyond itself in its use or purpose. Such an attitude results in creating what John Lachs has termed the "intermediate man"; someone who has only a mediated relation with the world and is, consequently, robbed of all immediate experience.
} 
kind of understanding available to us is the kind offered by the mind. Unlike Pascal and Scheier before us, who knew that "the heart has reasons that the mind knows not of," the methods we have been using to understand emotion fail to accord any dignity or value to the understanding that comes from emotion as it is expressed by the feelings. This is why, on its face, Roberts' statement raises little concern, and it is only when his research strategy is phrased in the latter form do we dare to make it suspect. After all, the nature of a thing does have quite a bit to say as to how we shall pursue it, to wit, we typically do not eat soup with a fork.

Nor am I just a "voice crying in the wilderness"; others have taken note of this need as well. Keith Oatley, in his book Best Laid Schemes, notes the need for a change of what he terms "style" in studying emotion - a change that relies more on the expression of emotion than on the traditional approaches to understanding emotion.

A psychology of the emotions will not, however, be of interest just for its technical applications. It should also enable us to derive insights. This is where some works on the psychology of emotions have faltered. They are written in the style favored by academic psychology that implies technical application, when it is insight that is being sought.

If natural science and technology allow us to operate reliably in the outer world, we can think of insight as allowing us to understand our own inner world and the inner world of others. For this to be possible we must be able to make aspects of such worlds of ourselves and others accessible and even salient. This requires a style of the kind more traditionally associated with poetry, theater, novels - with narrative ... In a psychology of emotions in which there is the possibility of insight, styles are needed that engage our emotions and thereby allow us to reflect on them. (Oatley, 1992, pp. 5-6). (My emphasis)

Elsewhere (Cogan, 1994, pp. 277-284) I note this and other strengths of Oatley's book but in this essay I would like to build on one particular insight of Oatley's approach: that if we are to have any meaningful understanding of emotion, we must start by engaging it; and that it is at this point that the methodology of western philosophy has failed us.

When I say that we must start by engaging emotion, I am appealing to the fact that an alternative understanding of emotion is provided by emotion itself. This is a reflexive understanding that comes in the expressing of emotion, an understanding that not only discloses the meaning of the particular triggering

\footnotetext{
${ }^{2}$ Blaise Pascall, The Thoughts of Blaise Pascal (Garden City, N. Y.: Dolphin Books, 1961; repr., Westport, Conn.: Greenwood Press, Inc., 1978), 98.
} 
event, but also is a leading clue to the nature of emotion itself. This feature of emotional expression, insight and understanding, is often overlooked. ${ }^{3}$

Take, for instance, two very different accounts of emotion, Sartre's phenomenological account (Sartre, 1948) ${ }^{4}$ and Harvey Green's analytic account (Green, 1992). Each, in its own way, attempts to give an understanding of emotion based on the project of its author-an understanding, moreover, which attempts to be faithful to the phenomenon itself. It is the condition of fidelity, however, that is ultimately compromised, since the term "fidelity" suggests that the final account of emotion given by each methodology will be a whole account, i.e., it will neither add extraneous material nor leave anything out. Yet the ability of emotion to offer insight is an aspect of emotion that is neither mentioned nor touched upon by either of these accounts; and it is one that rewards any effort of scrutiny. In fact, it is a feature of emotion that proves to be useful in achieving, not only a more radical understanding of the nature of emotion, but also a broader understanding of the prejudices we have that inevitably infect our study of it.

Without going into detail let me just briefly mention that both accounts notice that emotion is an intending of a world; that emotion represents, embodies, or in some sense is related to beliefs about the world. In fact, much is said in both accounts about many of the features of emotion up to and including the expression of emotion, but what, to me, is conspicuously absent is a noticing of the insight and understanding which comes in the expressing of emotion and in virtue of it.

\section{What Hangs in the Balance}

It might be a good idea to consider briefly just what is at stake in this issue of the appropriate methodology for studying emotion. I am claiming that various philosophical accounts we have of emotion are incomplete; indeed, they are misleading, because they are derived by means of a method that is ill suited to emotional phenomena and end up giving a flawed account. The consequences of this error are both profound and farreaching; but it is the reason for the error that should be the greatest cause for alarm.

Let me add here that I do not believe such omissions are accidental, but neither do I believe they arise by design. In order for them to be either, there would first have to be a thematic awareness of the role that emotion plays, and

\footnotetext{
${ }^{3}$ For a more detailed discussion of how the insight phenomenon arises in the expression of emotion, see my "Emotion and the Growth of Consciousness: Gaining insight through a phenomenology of rage" in Consciousness and Emotion 4:2 (2003), 205-239.

${ }^{4}$ For a more detailed analysis of Sartre's treatment of the emotions and how it fails, see (Cogan, 1995, pp. 21-34).
} 
I am claiming that this is the very thing that is absent. In the case of an accidental omission, a "Freudian" forgetting in the face of otherwise common knowledge would bring about the omission; or, in the case of omission by design, a deliberate taking notice of emotion and then calculatingly excluding it would effect the omission. To my mind, there is neither accident nor deliberation involved in the omissions of the respective accounts; rather, the omission is due to the fact that there is not a sufficient thematic awareness of the role that emotion plays in our experience. The authors simply do not see emotion for what it is and what it can offer; hence, such omissions are symptoms of what I will term philosophical myopia, since it is a kind of blindness.

This kind of blindness, however, is particularly dangerous in that it is a form of reductionism presented as the epitome of rationality. It is a disregarding of other options that, I will claim, is bom of an inability to see them; consequently, there is an attempt, by those who are blinded to these options, to explain everything in terms of what they can see-terms that are associated with qualifications that they create to be harmonious with what they can see. Here I am reminded of the fiscal frays that sometimes occur over funding for the humanities. The argument is generally made that only that behavior which can be quantified can count as education; and to get funding there has to be a demonstration that "education" is going on. Hence, since the arts and humanities deal in areas where educational accomplishments are not so quantifiable as they are, say, in the field of accounting, they are less likely to get the funding they need. This is an example where the conditions for funding were created out of the values of one group and then used as criteria for evaluating the values of another group. It also illustrates my point that the group setting the criteria are using criteria that "make sense" to them, i.e., they "see" the value in those criteria, and the values of the other group are, quite literally, invisible to them. Unfortunately, this tactic is not exhausted by fiscal disagreements; I am claiming that it has infected philosophy too. In what follows, I will explore what I take to be the cause of such blindness and suggest a possible first step in remedying it.

One implication of such an infection for philosophy is the sobering realization that the "love of wisdom," for which philosophy has famously been known and which is its namesake, has been occluded. If philosophy is myopic, then we can safely assume that there will always be something that it could see but doesn't see; hence, every account will remain dubious since there will always be the possibility that some aspect of the thing is unaccounted for owing to its not being seen. Another implication is that philosophy could go beyond offering incomplete accounts and wander completely into irrationality. This might come about by a kind of fanatical insistence by some that philosophy is not blind and that only the methodologies it has been using can ever show us the truth. But 
what is more irrational than a logical precept or methodology applied wholesale to the world irrespective of its suitability?

\section{A Closer Look at Philosophy}

If, as I have claimed, this omitting is neither accidental nor purposeful, how has it come about? In my view, Jung has pointed us toward the answser to this question. According to Jung, the personality of individuals permits of classification and can be determined according to certain criteria (Jung, 1990). He discovered that people differ in fundamental ways depending on (1) whether they are extraverted or introverted; (2) whether they lean more toward objective or subjective; and (3) the extent to which each individual emphasizes certain of the functions: thinking, feeling, sensing and intuition. The two attitudes of extraversion and introversion are mutually exclusive; they cannot coexist in consciousness simultaneously, although they can and do alternate with one another. It is the combination of attitudes and functions in varying proportions that gives rise to the different "types." Let me be clear that the types are categories into which people with similar but not necessarily identical characteristics are placed; and, even though individuals may share a category with others, no two individual personality patterns are exactly alike. The existence of types suggests that how we "function" could, in part, be due to solidly established preferences; and, furthermore, that such a preference for a given "function" could be characteristic and provide a criterion by which we could be "typed" by this preference. Jung suggested some "function types" or "psychological types," but it was the mother-daughter team of Katherine Cook Briggs and Isabel Briggs Myers who were able to bring a practical application of Jung's typology into play.

The commonly administered ${ }^{5}$ Myers-Briggs Type Indicator (MBTI $\left.{ }^{\circledR}\right)$ personality inventory was designed by Myers, and decades of research by such institutions as the Educational Testing Services (ETS) have since gone into it. One of the valuable uses of this inventory is to assist individuals in picking a vocation for which they are temperamentally suited. As I mentioned above, the MBTI ${ }^{\circledR}$ is based on Jung's ideas about perception and judgment, so the aim of the MBTI ${ }$ is to identify, by self-report of easily recognized reactions, the basic preferences of people in regard to perception and judgment, so that the effects of each preference, singly and in combination, can be established by research and put into practical use by identifying a suitable occupation.

\footnotetext{
${ }^{5}$ According to the Center for Applications of Psychological Type, approximately 2,000,000 people a year take the MBTI.
} 
The MBTI ${ }^{\circledR}$ contains four separate indices; each index reflects one of four basic preferences that, on Jung's theory, direct the use of perception and judgment. According to the Center for Applications of Psychological Type (CAPT), "the preferences affect not only what people attend to in any given situation, but also how they draw conclusions about what they perceive." The indices, along with their identifying letters, are: Extraversion-Introversion (EI), Sensing-iNtuition (SN), Thinking-Feeling (TF), and Judgment-Perception (JP). ${ }^{78}$ The theory is that each person will prefer one or the other pole of each pair, with these choices themselves being weighted. The completed profile will be made of the four letters indicating the pole of preference in each index, e.g., ENFJ (Extroversion, Intuitive, Feeling, Judging). A career consultant can interpret how a specific "type" is related to different groups of occupations and workplace issues, such as how one communicates or performs on a team, and make a recommendation based on that information. This instrument benefits the user by identifying, not only how information is received and processed by the user according to judgment and perception, but also the kind of organization, office setting, and work system that best suit his or her personality "type" and allowing the consultant to discuss the pros and cons of selecting particular occupational areas based on "type."

It is a curious thing to note that the profession of philosopher is vaunted as a profession for those who are typed as INTP, ${ }^{8}$ meaning they have a personality

${ }^{6}$ http://www.capt.org My emphasis.

${ }^{7}$ Extraversion-Introversion (EI). The EI index is designed to reflect whether a person is an extravert or an introvert in the sense intended by Jung. Jung regarded extraversion and introversion as „mutually complementary" attitudes whose differences ,generate the tension that both the individual and society need for the maintenance of life." Extraverts are oriented primarily toward the outer world; thus they tend to focus their perception and judgment on people and objects. Introverts are oriented primarily toward the inner world; thus they tend to focus their perception and judgment upon concepts and ideas. Sensing-Intuition (SN). The SN index is designed to reflect a person's preference between two opposite ways of perceiving; one may rely primarily upon the process of sensing $(\mathrm{S})$. which reports observable facts or happenings through one or more of the five senses; or one may rely upon the less obvious process of intuition $(\mathrm{N})$, which reports meanings, relationships and/or possibilities that have been worked out beyond the reach of the conscious mind.

Thinking-Feeling (TF). The TF index is designed to reflect a person's preference between two contrasting ways of judgment. A person may rely primarily through thinking (T) to decide impersonally on the basis of logical consequences, or a person may rely primarily on feelings (F) to decide primarily on the basis of personal or social values.

Judgment-Perception (JP). The JP index is designed to describe the process a person uses primarily in dealing with the outer world, that is, with the extraverted part of life. A person who prefers judgment (J) has reported a preference for using a judgment process (either thinking or feeling) for dealing with the outer world. A person who prefers perception $(\mathrm{P})$ has reported a preference for using a perceptive process (either $\mathrm{S}$ or $\mathrm{N}$ ) for dealing with the outer world.

${ }^{8}$ See, http://www.intp.org/job.html for a list of "likely INTP occupations." 
type that is weighted in favor of Introverted, iNtuitive, Thinking, and Perceptive. And, given the work that philosophers do and the social image of their role, we would quite naturally assume that these personality traits would suit them to their task quite well. However, we can very easily disabuse ourselves of this notion by taking pause to consider seriously at least one of the implications of the Myers-Briggs type designation, namely, the implication that not only does each letter indicate a particular "preference" or "strength" in the type, it also indicates what trait is absent, weak, or less preferred. Thus, when we see that the philosopher is introverted we also know that he or she is not extraverted; similarly with intuitive, thinking and perceptive, we know immediately that sensing, feeling and judging are less preferred and very likely greatly diminished in some cases.

The personality inventory predicts that the type best suited to do philosophy is one where the free expression of feeling is eclipsed by thinking, where sensing defers to intuition, and where overt social interaction is subverted by introversion. This fact gives one pause to consider whether philosophers are the ones best suited to tell us about emotion after all, especially if what is needed in studying emotion is the free expression of feeling. On the other hand, those caught in the throes of sensation and emotion seldom have the perspective on feeling that is necessary to give a coherent account of it. What is wanted in this situation is some direction and a sense of balance, but how are we to achieve it?

Let me issue a caveat here by way of drawing attention to what I believe is obscured by the $\mathrm{MBTI}^{\circledR}$ : it obscures that being "suited" to a job is an ambiguous designation. It means both that I have a particular skill that will ensure that I can perform the job well, and that I am "typically" similar to others who do that job now, and so will "fit in" socially and find the job "satisfying" to me. Thus, "suited" means both suited to perform the task owing to special skills and suited socially to the job by being typically similar to others who do that job. Indeed, it is just these very two senses that are fleshed out during the interview process in many jobs; the first interview determines whether the skills are present and the subsequent interviews are used to determine how well someone will "fit in" with the others at work-whether there is "chemistry" between the interviewer and the interviewee that will carry over into the workplace.

However, it does help us in the matter of predicting which of these two senses will probably hold sway if we are either the interviewer or the interviewee. For some, having a particular skill does not mean that they are attracted to the job for which their skill makes them suited-preferring, instead, a particular type of esprit de corps and camaraderie among their co-workers. For such people, those with whom one works are more important than the job or how well its done-or even how important the job is. Similarly, there are those who care only for the opportunity to do that for which they have great skill and care little about socializing with their co-workers or how "congenial" their workplace environment is. 
Hence, when the data report that INTP people are suited to teaching philosophy, part of what it means is that, demographically speaking and at the present time, a great number of INTP people have chosen to take up being philosophers. So, other INTP people who have the critical and analytical skills required in philosophy will feel socially comfortable in that job because they will be "likeminded" with their colleagues. It also means that an extroverted and freely expressive individual will probably not find it so comfortable, in spite of the fact that they have the critical, analytical, and teaching skills to do the job well. But even this is not a rule since it is entirely possible that whole departments of philosophy might be made up non-INTP people who, nonetheless, thrive in that situation.

Let me briefly summarize my position as I have developed it thus far. The mind has a perspective on the world that is different from the one that feeling has. If we are to get the "whole story" about ourselves and our world, we need to have both points of view. However, owing to a certain blindness toward feeling, philosophy has given undue weight and preference to the activity of mind. This preferential treatment has had the effect of giving us misleading accounts as regards the nature and import of emotion. I am claiming that what is needed by those who undertake to study emotion is a research strategy that includes engaging emotion from the side of feeling as well as from the side of mind. I will now suggest that those who aim to study emotion adopt, as an intermediary step on the way to engaging emotion at the feeling level, the ideal of rigor promoted by the phenomenologist Edmund Husserl.

\section{Phenomenological Rigor}

Edmund Husserl (1965), in his "Philosophy as Rigorous Science," put forth an argument that might make my point about rigor much better than I can make it; so let me summarize that argument here. Science makes pronouncements about the world and the nature of reality. These pronouncements are the synthesis of conclusions arrived at by means of experimentation in accord with hypotheses - experimentation, I might add, that has been carefully and meticulously corroborated by others within the global scientific community who were willing to adhere to the same rules of experimentation.

But this experimentation has been carried out with quite ordinary equipment and the results tallied with quite ordinary implements. By "ordinary" I do not mean that you might find this equipment in anyone's house or that one can come by it in any department store; I mean primarily that some of the equipment and implements are part of the everyday world and experience of the scientist, even if not the proverbial "man on the street." 
Because these implements and this equipment are part of the everyday world of the scientist, the scientist, more or less, takes them for granted as "already being there." It is, after all, the reality of the equipment and implements that ultimately guarantees the validity of the experiments and the theoretical results those experiments yield. Indeed, the scientist takes much more than just this for granted; he or she also takes the working of the world for granted. So, in the final analysis we can say that the end results of the scientist's work really rests on the validity of the assumptions used to arrive at those results, viz., the assumptions that are an integral and essential part of the everyday lifeworld of the scientist and of every other individual.

Thus, if we are ever to have a clear and robust foundation for our scientific results, we must first spell out the meaning structure of all the assumptions that undergird, and ultimately ground, our scientific work; namely, the meaning structure of the everyday life-world. Let me illustrate this with an anecdote from my days of high school geometry. Very often the students in our class could see the correct answer to a particular problem on the basis of intuition without ever having to go through the proof. But the point of doing geometry wasn't to get the right answer so much as it was to get the right answer in the right way - and the right way was to trace the answer all the way back to the axioms so that it would be properly grounded and proved - the axioms, of course, are the assumptions that were taken for granted. The phenomenologist seeks to do the same thing and makes no judgment about the validity of the findings of science; rather the phenomenologist strives only to ground those findings in the "axioms"- the assumptions found in the logic and meaning structure of the life-world.

It should stand to reason that if certain findings cannot be grounded there, or if they contradict the legitimacy of the life-world, they can hardly be counted as rigorous science. For instance, based on what we know of aerodynamics, science tells us that it is possible for bumblebees to fly; hence, any formal scientific thesis to the effect that it is impossible for bumblebees to fly must be false. This is an admittedly simplistic example but it serves to illustrate that when, as a result of the mathematization of nature, science proclaims that it is only their own idealizations that are real, then those results are immediately suspect on the grounds that the equipment and implements (including such mundane things as pencil and paper) used to arrive at those conclusions had to be assumed to be real in order to yield the conclusions arrived at; hence, the inescapable conclusion that the idealizations of science are not the only things that are real.

Thus, if the conclusion, that only the idealizations of science are real, is held to be true, it has the dubious distinction of being grounded in the unreal, viz., the paper, pencil, and other mundane things used to reach that conclusion. For this reason, the general argument and aim of the phenomenologist is simply 
to hold the scientists true to their own standard of rigor - a standard that requires the implementation of a procedure, viz., an experiment to validate a hypothesis. Although the scientist requires the procedure for validation of the hypothesis, the validity of the procedure qua procedure, in so far as procedure always involves the use of objects taken from the everyday life-world, is never questioned and is assumed quite naively.

It is precisely this naivete that the phenomenologist brings to the surface in order to subject it to a more pointed interrogation and scrutiny. This interrogation and scrutiny is required of all endeavors because every endeavor is ultimately grounded in the life-world and the theoretical results of all research in those endeavors rest upon the meaning structure and "validity" of the life-world. This is only to say that the results of every science, indeed, every theoretical endeavor, are not secured until the foundation upon which those results rest is secured; and that foundation, in every case, is the life-world. So, to do a phenomenology of something is only to show, by means of rigorous and careful description, how that thing is related to, and grounded by, the meaning structure and logic of the life-world; first by means of a static phenomenology, then a genetic, and ultimately a generative phenomenological description. ${ }^{9}$ Unless such a description is in place, the results of any theoretical endeavor are no more legitimately grounded than were the geometry student's intuition referred to above, no matter whether that intuition or those results are correct or not.

What is at issue here, as in the case of my geometry example, is not whether we get the right answer from the sciences and other theoretical endeavors, but whether we can prove it $i$ the right answer by tracing it back to the axioms - and no proof is complete that stops before reaching that point. When we see phenomenology in this light, it is apparent that it is not in competition with science but rather a complement to itphenomenology has not come to abolish science but to fulfill it, to make it truly rigorous.

\footnotetext{
${ }^{9}$ The terms "static," "genetic," and "generative" refer to the scope of the description given. In rough terms, a static phenomenology will disclose the structure of the object or "matter at hand" as it appears within its immediate context; a genetic phenomenology will go beyond this description and seek the broader connections that the immediate context has with the world; and the generative phenomenology will strive to articulate the connections over generations, that is, over and through time. Thus, the static phenomenology of a coffee mug will reveal that when it is given it is given as an extended object having such and such heft, a back side, colored, etc. The genetic description will reveal that the mug is also given as a coffee mug, that is, we recognize its use and its familiar shape; we may even recognize it as belonging to a particular person, or it may be a "Dunkin Donuts" mug or "Starbucks"; the generative phenomenology will reveal that, as a cultural object, it contains information about how we have moved from a tea drinking society, in the days of the Boston Tea Party, to a coffee drinking society, along with all of the economic and social implications of that move.
} 
Applied to the case of philosophy and emotion, what this means is that, since the expressing of emotion is part of the "natural attitude" and, as such, part of the logical fabric making up the meaning-structure of our experience, then every account that purports to be a philosophical account of emotion must include a descriptive account of what it means to express emotion. This can be accomplished only by expressing emotion and describing what occurs. After all, isn't this what the scientists do with natural laws? What we call the "laws" of nature are simply descriptions of how nature behaves, not edicts demanding a certain kind of behavior. It would be an impoverished philosophy indeed whose accounts bore no resemblance to our experience, while vaunting their own internal logical coherence.

\section{Conclusion}

In this essay I have claimed that some methodologies of western philosophy have failed us in the matter of understanding emotion insofar as they have omitted key features of the emotional experience in their accounts of emotion. I alluded to Sartre's phenomenological account of emotion and Green's analytic account as examples illustrating this claim. I further claimed that this oversight was neither accidental nor by design but was due to the fact that there was not a sufficient thematic awareness of the role that emotion plays in our experience. In an effort to explain the absence of such an awareness, I introduced the MBTI ${ }^{\circledR}$ personality inventory. According to this indicator, individuals have a personality type that falls into one of sixteen possible categories depending on which pole of four separate indices is preferred. Since one of the valuable uses of this inventory is to assist individuals in choosing a "suitable" profession, I noted that the profession of philosopher was currently a likely, although not necessary choice by those whose profile was INTP, indicating a personality type that is weighted in favor of Introverted, iNtuitive, Thinking, and Perceptive.

I further noted that, if what is needed in studying emotion is the ability to engage it, that is, to actually feel the feelings of emotion, then it would seem that philosophers who evince a profile that makes them disinclined to express feelings and emotion might not be the best ones suited to that task after all, since, based on their profile, they would be least likely to evince a preference to actually feel the feelings of emotion.

I then suggested that an intermediary step that might be taken would be to embrace the ideal of rigor promoted by the phenomenologist Edmund Husserl, since it is an ideal that is intellectually rigorous yet demands careful attention to the details of actual experience - the net effect of which is that it offers a rigor that exceeds what is commonly taken as scientific rigor. 
Hence, the main conclusion to be drawn is that if philosophy wants to be able to give an accurate account of the nature of emotion and the role that it plays in our experience, then it must adopt a research strategy that includes the expression of emotion as well as the intellectual analysis of it. It must give us a whole account of our experience and not one that is weighted in favor of either the perspective of the mind or the perspective of the feelings. ${ }^{10}$ Indeed, what is needed is for philosophers to give us the kind of rigorous description of emotion that phenomenology promises, and this can come about only if a new research strategy is adopted that can see the expression of emotion as an avenue of knowledge and insight, and not just as a bothersome and useless epiphenomenon.

\section{References}

Cogan, J.M. (1994). A place for emotion in critical study. Human Studies, 17: 277-284. Cogan, J.M. (1995). Emotion and Sartre's two worlds. Journal of Phenomenological Psychology, 26: 21-34.

Cogan, J. M. (2003). Emotion and the growth of consciousness: Gaining insight through a phenomenology of rage. Consciousness and Emotion, 4 (2): 205-239.

Green, H. O. (1992). The Emotions: a Philosophical Theory. Dordrecht: Kluwer Academic Publishers,

Husserl, E. (1965). Phenomenology and the Crisis of Philosophy. New York: Harper \& Row.

Jung, C. G. (1990). From "Psychological types." In V. de Laszlo (ed). The Basic Writings of C. G. Jung (187-297). Princeton: Princeton University Press.

Oatley, K. 1992. Best Laid Schemes. Cambridge: Cambridge University Press.

Pascall, B. 1978. The Thoughts of Blaise Pascal. Garden City, N. Y: Dolphin Books. repr., Westport, Conn.: Greenwood Press, Inc.

Roberts, R. C. 2003. Emotions: An Essay in Aid of Moral Psychology. Cambridge: Cambridge University Press.

Sartre, J. P. 1948. The Emotions: Outline of a Theory. New York: The Wisdom library a division of Philosophical Library.

\footnotetext{
${ }^{10}$ Of course, a truly whole philosophy would find the harmonious balance of heart, body, and mindlove, power, and wisdom - but here I address only the need to correct the overlooking of emotion.
} 